\title{
Somatic mutations of KIT in familial testicular germ cell tumours
}

\author{
EA Rapley*, , S Hockley', W Warren', L Johnson', R Huddart', G Crockford², D Forman'2, MG Leahy²,

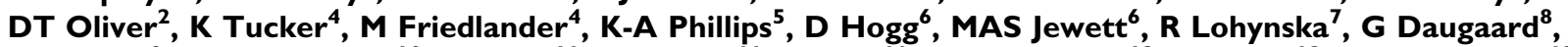 \\ S Richard", A Heidenreich $^{10}$, L Geczi "', I Bodrogi ", E Olah"1, WJ Ormiston' ${ }^{12}$, PA Daly'2, LHJ Looijenga ${ }^{13}$,

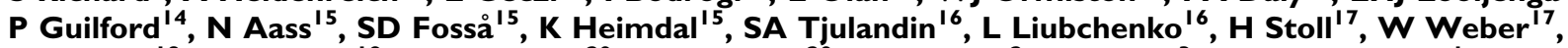 \\ L Einhorn $^{18}$, BL Weber ${ }^{19}$, M McMaster ${ }^{20}$, MH Greene ${ }^{20}$, DT Bishop ${ }^{2}$, D Easton ${ }^{3}$ and MR Stratton'
}

'Section of Cancer Genetics, Institute of Cancer Research, Brookes Lawley Building, 15 Cotswold Road, Sutton, Surrey SM2 5NG, UK; ${ }^{2}$ Genetic Epidemiology Division, Cancer Research UK Clinical Centre, St. James's University Hospital, Leeds LS9 7TF, UK; ${ }^{3}$ Cancer Research UK Genetic Epidemiology Unit, Strangeways Research Laboratory Worts Causeway, Cambridge CBI 8RN, UK; ${ }^{4}$ Department of Medical Oncology, Division of Medicine, University of New South Wales and Prince of Wales Hospital Randwick, Sydney, Australia; ${ }^{5}$ Department of Haematology and Medical Oncology Peter MacCallum Cancer Centre, St Andrews Place, East Melbourne, Victoria 3002, Australia; ${ }^{6}$ Princess Margaret Hospital and University of Toronto, 610 University Avenue, Toronto, ON, Canada M5G 2M9; 'Department of Radiotherapy and Oncology, University Hospital, V Uvalu 84, I50 06 Prague, Czech Republic; ${ }^{8}$ Department of Oncology 5073, Rigshospitalet, Copenhagen, Denmark; ${ }^{9}$ Génétique Oncologique EPHE Faculté de Médecine Paris-Sud, UPRESS 1602 and Service d'Urologie, CHU, 94276 Le Kremlin-Bicêtre, France; ${ }^{10}$ Department of Urological Oncology, Phillips University, Marburg, Germany; " Department of Chemotherapy C and Department of Molecular Genetics National Institute of Oncology, Rath Gyorgy u. 7, H-I I 22 Budapest, Hungary; ${ }^{12}$ Department of Medical Oncology, St James Hospital, Dublin, Ireland; ${ }^{13}$ Pathology/Laboratory For Experimental Patho-Oncology, Erasmus University Medical Center Rotterdam/Daniel den Hoed Cancer Center, Josephine Nefkens Institute, 3000 DR Rotterdam, Netherlands;

${ }^{14}$ Cancer Genetics Laboratory, University of Otago, PO Box 56, Dunedin, New Zealand; ${ }^{15}$ Department of Oncology, The Nonwegian Radium Hospital and Department of Medical Genetics, Rikshospitalet 0027 Oslo, Nonway; ${ }^{16}$ Laboratory of Clinical Genetics, Institute of Clinical Oncology, NN Blokhin Russian Cancer Research Center, Kashirskoye sh., 24, Moscow 115478, Russian Federation; ${ }^{17}$ Clinical Cancer Research Unit, UICC Familial Cancer and Prevention Project Heuberg $16 \mathrm{CH}-405$ I Basel, Switzerland; ${ }^{18}$ Indiana University, Indianapolis, IN, USA; ${ }^{19}$ Abramson Family Cancer Research Institute, University of Pennsylvania, PA USA; ${ }^{20}$ Clinical Genetics Branch, Division of Cancer Epidemiology \& Genetics, National Cancer Institute National Institutes of Health , 6120 Executive Boulevard, Room Rockville, MD 20852- 7231, USA

Somatic mutations of the KIT gene have been reported in mast cell diseases and gastrointestinal stromal tumours. Recently, they have also been found in mediastinal and testicular germ cell tumours (TGCTs), particularly in cases with bilateral disease. We screened the KIT coding sequence (except exon I) for germline mutations in 240 pedigrees with two or more cases of TGCT. No germline mutations were found. Exons 10, II and 17 of KIT were examined for somatic mutations in 123 TGCT from 93 multiple-case testicular cancer families. Five somatic mutations were identified; four were missense amino-acid substitutions in exon 17 and one was a 12 bp in-frame deletion in exon II. Two of seven TGCT from cases with bilateral disease carried KIT mutations compared with three out of I 16 unilateral cases $(P=0.026)$. The results indicate that somatic KIT mutations are implicated in the development of a minority of familial as well as sporadic TGCT. They also lend support to the hypothesis that KIT mutations primarily take place during embryogenesis such that primordial germ cells with KIT mutations are distributed to both testes.

British Journal of Cancer (2004) 90, 2397-240I. doi:I0.1038/sj.bjc.6601880 www.bjcancer.com

Published online 18 May 2004

(c) 2004 Cancer Research UK

Keywords: KIT; testicular germ cell tumours

Testicular germ cell tumours (TGCTs) are the most common malignancy in males between the age 15 and 45 years (Ferlay et al, 2001). There are several risk factors for TGCT including previously diagnosed TGCT, undescended testis (UDT) and a family history of the disease. TGCT has been one of the highest familial relative risks of any cancer syndrome with reported increased risks of 8 10-fold to brothers and 4-6-fold to fathers (Forman et al, 1992; Heimdal et al, 1996). We previously described linkage of familial testicular cancer to a locus (TGCT1) at Xq27 (Rapley et al, 2000). This locus was particularly strongly associated with families

*Correspondence: Dr EA Rapley; E-mail: Liz.raphy@icr.ac.uk Received 31 October 2003; revised 13 February 2004; accepted 25 March 2004; published online 18 May 2004 characterised by at least one case of bilateral testicular cancer. The results indicated, however, that only a minority of families are attributable to this locus and that additional TGCT susceptibility genes are likely to exist.

The KIT gene encodes a type III transmembrane tyrosine kinase receptor. KIT is expressed in several cell types where it regulates primordial germ cell migration, proliferation and apoptosis during foetal gonad development (Mauduit et al, 1999). KIT has been shown to be expressed in some TGCT (Strohmeyer et al, 1995; Bokemeyer et al, 1996) and somatic mutations in KIT have recently been identified in testicular (Tian et al, 1999) and mediastinal germ cell tumours (Przygodzki et al, 2002). Mutations have been reported in a high proportion of patients with bilateral disease, and in a much smaller proportion of unilateral cases (Looijenga et al, 2003). When both tumours from bilateral cases could be examined, 
the same mutation was present in both tumours. Together, these results suggest that somatic KIT mutations occur early in embryogenesis, before the primordial germ cells have divided and migrated to the gonads. As a consequence, primordial germ cells with KIT mutations are distributed to both testes and hence KIT mutations are associated with bilateral disease (Looijenga et al, 2003).

Previous studies have indicated that KIT mutations found in germ cell tumours are somatic. To investigate further the role of KIT in predisposition to TGCT, and the role of somatic mutations in familial tumours, we have examined a series of constitutional and tumour DNAs from patients with TGCTs and a family history of the disease.

\section{MATERIALS AND METHODS}

The International Testicular Cancer Linkage Consortium (ITCLC) has obtained samples from 326 families with two or more cases of TGCT (Table 1). For this study, we analysed DNA extracted from blood lymphocytes (constitutional DNA) from one affected individual from each of 240 families, for whom the DNA was most readily available. The pedigree structure for these families is shown in Table 1 . We also examined tumour materials from 123 cases from 93 families; for 15 of these families, the tumour material only was available and these were therefore not included in the 240 constitutional DNA set (Table 1). Seven tumours were from patients with bilateral disease, but the tumour material was only available from one of each pair of tumours arising in these patients.

Patients donated samples and medical information with full informed consent and with local or national ethical review board approval. Information on clinical status including type of TGCT, age of diagnosis, presence of UDT and laterality of disease was confirmed by reviewing histological reports and clinical notes.

DNA was prepared from whole blood and from formalin-fixed, paraffin-embedded tumour sections using standard techniques. The tumour material was microdissected to minimise contamination by surrounding normal tissue. Primer sequences for KIT were designed from the KIT mRNA and genomic sequence (Ensembl

Table I Pedigree structure of cases with family history of TGCT used in KIT mutation search

\begin{tabular}{|c|c|c|c|}
\hline Family type & $\begin{array}{l}\text { Pedigrees (by type) } \\
\text { identified by ITCLC }\end{array}$ & $\begin{array}{l}\text { Number of pedigrees analysed } \\
\text { (by type) using constitutional DNA }\end{array}$ & $\begin{array}{l}\text { Number of pedigrees analysed (by type) } \\
\text { using DNA from tumour material }\end{array}$ \\
\hline Sib trios & 8 & 5 & 2 \\
\hline Sib pairs & 154 & 106 & $43(11)^{a}$ \\
\hline Father/son pairs & 52 & 46 & $16(2)^{a}$ \\
\hline Cousin pairs & 40 & 33 & 14 \\
\hline Uncle/nephew pairs & 32 & 23 & $13(2)^{a}$ \\
\hline Great grandfather/great grandson pairs & i & 0 & । \\
\hline Total & 326 & 240 & 93 \\
\hline
\end{tabular}

${ }^{a}$ Number in brackets represents pedigrees (by subtype) for which only tumour material was available for analysis, these families are not included in the KIT analysis of constitutional DNA samples.

Table 2 KIT gene primer pairs

\begin{tabular}{|c|c|c|c|}
\hline Exon & Forward & Reverse & PCR product size \\
\hline Exon2b & CTTGGCAGGCTCTTCTCAAC & CCTTCTAGACCCAGCCAGAA & 395 \\
\hline Exon3a & GTGCGTGATACATGGAAAGC & GTAGGCGCGTTTCACACTTT & 397 \\
\hline Exon4 & GATAGGTTAGCACCATGCTTTG & TCTCCCAGACAATCCACCTC & 400 \\
\hline Exon5 & TGGAGAAGTTAATTGCTGCTATाT & TCATTCATTCAGTGATAACAAAATTC & 389 \\
\hline Exon6 & GGAAATCAACCAATTGTTITTG & TCGTGGATITACGGGTTACA & 384 \\
\hline Exon9 & ATGCCACATCCCAAGTGTIT & TGACATGGTCAATGTTGGAA & 364 \\
\hline Exonlo & AACCAAGGTGAAGCTCTGAGAC & СТССТСАAСАACСТТССАСТG & 384 \\
\hline Exon 10 small & ATCCCATCCTGCCAAAGTT & CTGTGGGGAGAAAGGGAAA & 246 \\
\hline Exonll & TAGCTGGCATGATGTGCATT & GGCGCAATTTCACAGAAAAC & 397 \\
\hline Exon II small & AGAGTGCTCTAATGACTGAGACAA & AAACAAAGGAAGCCACTGGA & 279 \\
\hline Exon 12 & ATTGCGCCCCTTTTGATAG & GTTCAGACATGAGGGCTTCC & 392 \\
\hline Exon 13 & TGCTCAAGCGTAAGTTCCTG & GCAAGAGAGAACAACAGTCTGG & 335 \\
\hline Exon 17 small & TAAATGGTTITCTTITCTCCTCCA & TTCGATAAAATTGTTTCCTGTGA & 233 \\
\hline Exon 18 & CTCCACATTCAGCAACAGC & GGCTGCTTCCTGAGACACA & 333 \\
\hline Exon 19 & AAGTGGATGGCACCTGAAAG & СССTCAACATCTGGGTITCT & 390 \\
\hline Exon20 & TCCATATGTCCAGTTGCATAGC & GCCCAATTGCAACCTAAGA & 350 \\
\hline Exon21 & TTCCATCAGTTAGTTGTGATCTTG & GACAAAAATCATCGGCCACT & 390 \\
\hline
\end{tabular}


gene ID = ENSG00000157404), using the Primer3 software (http:// www-genome.wi.mit.edu/cgi-bin/primer/primer3_www.cgi). Primer sequences for the $21 \mathrm{KIT}$ exons and PCR product sizes are shown in Table 2. Exons $>400 \mathrm{bp}$ were amplified using overlapping primer pairs. A total of 23 primers pairs were used to examine the coding region of the KIT gene. Primers designed for exon 1 failed to amplify under a variety of PCR conditions and were redesigned but again failed to give a PCR product. Exon 1 was therefore not examined. Mutations of KIT are predominantly located in exons 10, 11 and 17 (Pignon et al, 1997; Tian et al, 1999; Rubin et al, 2001; Przygodzki et al, 2002; Looijenga et al, 2003); therefore, the tumour material was examined only at these exons. Primers generating a smaller sized PCR fragment were designed for exons 10,11 and 17 to allow easy amplification from paraffin-embedded material and were specifically used to analyse the tumour material.

For constitutional DNA, all exons were examined by conformation sensitive gel electrophoresis (CSGE) (Ganguly et al, 1993). Briefly, both PCR primers were labelled with adenosine $5^{\prime}\left[\gamma-{ }^{32} \mathrm{P}\right]$ triphosphate by $\mathrm{T} 4$ polynucleotide kinase. After amplification, PCR products were heated to $98^{\circ} \mathrm{C}$ and cooled down to $60^{\circ} \mathrm{C}$ over $30 \mathrm{~min}$ to allow heteroduplex formation. PCR samples were run on a CSGE gel $\left(10 \% \mathrm{vv}^{-1}\right.$ ethanediol, $13.75 \% \mathrm{vv}^{-1}$ formamide, $15 \% \mathrm{vv}^{-1}$ acrylamide with $4 \mathrm{mg} \mathrm{ml}^{-1}$ piperazine and $1 \times$ GTB buffer $(89 \mathrm{~mm}$ Tris, $29 \mathrm{~mm}$ taurine and $0.5 \mathrm{~mm}$ EDTA). Polymerase chain reaction (PCR) products from samples that showed migration shifts on CSGE were bidirectionally sequenced using the BigDye terminator v3 sequencing kit and a 3100 automated sequencer (Applied Biosystems, Warrington, UK).

All tumour samples were examined for exons 10, 11 and 17 of the KIT gene by direct sequencing. The tumour material was amplified and sequenced using specifically designed primers that generated a smaller sized PCR fragment than those designed for CSGE analysis and allowed for ease of amplification from tumour material. Sequencing was performed using the BigDye terminator v3 sequencing kit and a 3100 automated sequencer (Applied Biosystems).

Differences in distribution between categorical variables were assessed with the appropriate contingency table test.

\section{RESULTS AND DISCUSSION}

In total, 240 constitutional DNA samples from TGCT cases with a positive family history were examined using CSGE. Two con- servative nonsynonymous constitutional sequence variants were detected, M541L and V399I (Table 3). M541L was found in 43 out of $240(17.9 \%)$ cases and it is a common polymorphism found in 32 out of $192(16.6 \%)$ of normal controls. V399L was found in only a single case and was not found in 200 controls. V399 is not conserved in other species (mouse, zebrafish and xenopus) and the amino-acid substitution is conservative, suggesting that this variant is a rare polymorphism rather than a disease-causing change. Overall, the results provide no evidence that germline KIT mutations are associated with an increased risk of testicular cancer.

Somatic mutations of KIT were detected in five out of 123 TGCTs examined (Table 4 and Figure 1). Three mutations involved codon 816, a known hotspot for KIT mutations in testicular (Tian et al, 1999; Przygodzki et al, 2002; Looijenga et al, 2003) and other cancers (Rubin et al, 2001). Another mutation involved codon 820 , an infrequently mutated residue but one that has been previously reported (Pignon et al, 1997). The fifth mutation was a $12 \mathrm{bp}$ deletion encoding a 4 amino-acid in-frame deletion in the cytoplasmic juxamembrane domain of KIT. In-frame deletions of this region are common in gastrointestinal stromal tumours (GIST) (Rubin et al, 2001) but have not been documented in TGCT. All these mutations were shown to be somatic. Two out of seven (28.5\%) familial bilateral cases carried a somatic KIT mutation compared with three out of $116(2.6 \%)$ familial unilateral cases $(P=0.026$, Fisher's exact test). Unfortunately, samples of the other tumour/ITGCN from the two bilateral cases with KIT

Table 3 Sequence variants in KIT detected in constitutional DNA from patients with familial TGCTs

\begin{tabular}{lllc}
\hline Exon & $\begin{array}{l}\text { Nucleotide } \\
\text { change RefSeq } \\
\text { NM_000222 }\end{array}$ & $\begin{array}{l}\text { Amino-acid } \\
\text { change }\end{array}$ & $\begin{array}{c}\text { Number of } \\
\text { cases }\end{array}$ \\
\hline 3 & G525A & Al68A & $\mid$ \\
6 & C999T & N326N & $\mid$ \\
7 & GI216A & V399| & $\mid$ \\
10 & Al642C & M54IL & 43 \\
10 & Al659G & K546K & 5 \\
16 & C2370T & L783L & 1 \\
17 & C245IT & I7981 & 12 \\
18 & G2607C & L862L & 53 \\
19 & G2643A & P874P & 1 \\
\hline
\end{tabular}

Table 4 Sequence changes in KIT detected in TGCTs

\begin{tabular}{|c|c|c|c|c|}
\hline $\begin{array}{l}\text { Sample } \\
\text { name }\end{array}$ & Exon & $\begin{array}{l}\text { Nucleotide change RefSeq } \\
\text { NM_000222 }\end{array}$ & Amino-acid change & $\begin{array}{l}\text { Case details giving tumour type, age at diagnosis, } \\
\text { history of undescended testis and family history }\end{array}$ \\
\hline $2158-201$ & 11 & Del $1675-1686$ & del MYEV AA 552-555 & $\begin{array}{l}\text { R. sem and L.ITGCN } \\
\text { Age at diagnosis = } 39 \text { years } \\
\text { History of bilateral UDT } \\
\text { Family history = sib pair }\end{array}$ \\
\hline 274-20। & 17 & A2480G & D820G & $\begin{array}{l}\text { L. sem } \\
\text { Age at diagnosis }=52 \text { years } \\
\text { Family history }=M Z \text { twins (twin brother has bilateral } \\
\text { disease, no tumour available for this patient) }\end{array}$ \\
\hline 295-304 & 17 & G2467C & $\mathrm{D} 816 \mathrm{H}$ & $\begin{array}{l}\text { R. mixed and L. sem }{ }^{\mathrm{a}} \\
\text { Age at diagnosis }=39 \text { and } 55 \text { years } \\
\text { History of UDT } \\
\text { Family history }=\text { sib trio }\end{array}$ \\
\hline $377-1664$ & 17 & G2467T & D816Y & $\begin{array}{l}\text { R NS } \\
\text { Age at diagnosis }=66 \text { years } \\
\text { Family history }=\text { father/son pair }\end{array}$ \\
\hline
\end{tabular}

${ }^{a}$ Tumour examined in bilateral cases. Sem = Seminoma; NS = nonseminoma; ITGCN = intratubular germ cell neoplasia; $R=$ right side; $L=$ left side; UDT = undescended testis. 
1

a

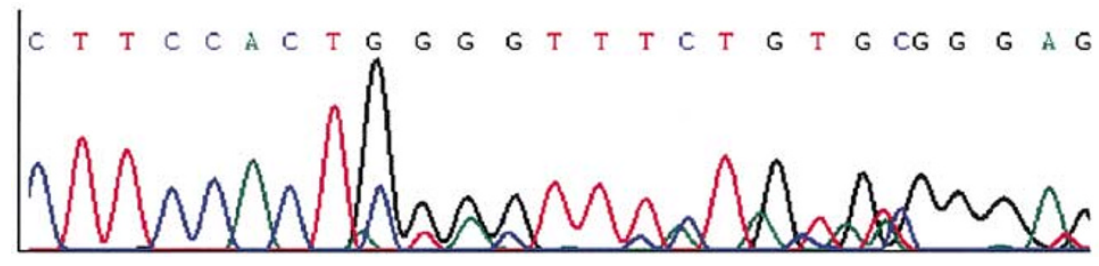

b

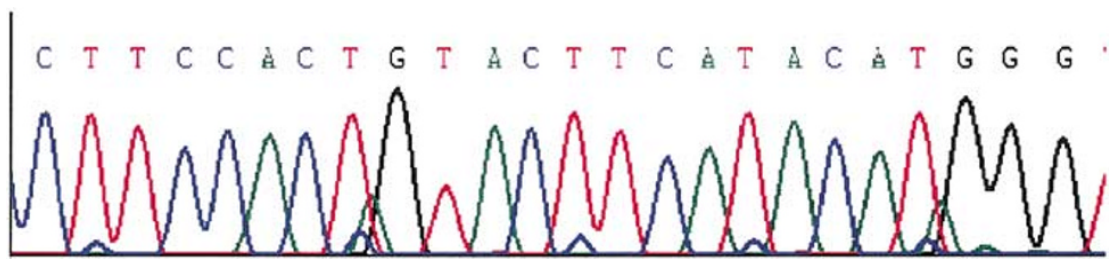

12 bp deletion in sample 2158-201 (reverse sequence shown)

2

a

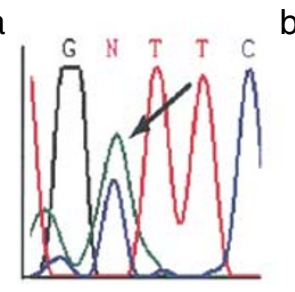
b

3

$A \rightarrow G$ sequence change resulting in D820G in sample 274-201

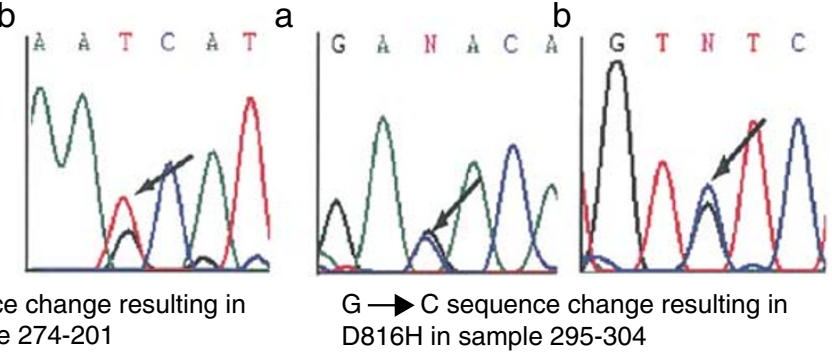

4

b

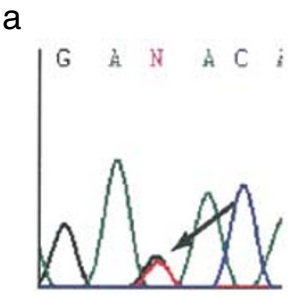

a

mutations were not available to evaluate the presence of the mutations. While the frequency of KIT mutations in unilateral TGCT is similar to that detected previously, the proportion of cases with bilateral disease is much lower despite the fact that we examined a larger proportion of the KIT gene than in the study by Looijenga et al (2003). The reason for this is unclear. However, it may indicate that bilateral disease in the context of familial testicular cancer has a different pathogenesis from sporadic bilateral cases and that most of the familial bilateral cases are explained by the elevated risk conferred by the underlying susceptibility genes. Nevertheless, the overall pattern of an elevated frequency of KIT mutations in bilateral compared to unilateral cases supports the observation of Looijenga et al (2003) and suggests that somatic KIT mutations may take place early in development.
In conclusion, our results indicate that constitutional mutations of KIT are not associated with a substantially increased risk of TGCT. Somatic mutations of KIT are found in familial TGCT tumours with a higher proportion in cases with bilateral disease. Overall, the proportion of KIT mutations in TGCT is low and other somatic and susceptibility genes must play important roles.

\section{ACKNOWLEDGEMENTS}

This work was supported by Cancer Research UK and Hungarian research Grants OTKA T030039 and OM Szechenyi NKFP/1/48/ 2001. 


\section{REFERENCES}

Bokemeyer C, Kuczyk MA, Dunn T, Serth J, Hartmann K, Jonasson J, Pietsch T, Jonas U, Schmoll HJ (1996) Expression of stem-cell factor and its receptor c-kit protein in normal testicular tissue and malignant germcell tumours. J Cancer Res Clin Oncol 122: $301-306$

Ferlay J, Bray P, Pisani P, Parkin DM (2001) GLOBOCAN 2000: Cancer Incidence, Mortality and Prevalence Worldwide, Version 1, IARC CancerBase No.5. Lyon: IARC Press

Forman D, Oliver RT, Brett AR, Marsh SG, Moses JH, Bodmer JG, Chilvers CE, Pike MC (1992) Familial testicular cancer: a report of the UK family register, estimation of risk and an HLA class 1 sib-pair analysis. $\mathrm{BrJ}$ Cancer 65: 255-262

Ganguly A, Rock MJ, Prockop DJ (1993) Conformation-sensitive gel electrophoresis for rapid detection of single-base differences in doublestranded PCR products and DNA fragments: evidence for solventinduced bends in DNA heteroduplexes. Proc Natl Acad Sci USA 90: $10325-10329$

Heimdal K, Olsson H, Tretli S, Flodgren P, Borresen AL, Fossa SD (1996) Familial testicular cancer in Norway and southern Sweden. Br J Cancer 73: $964-969$

Looijenga LH, de Leeuw H, van Oorschot M, Van Gurp RJ, Stoop H, Gillis AJ, de Gouveia de Brazoa CA, Weber RF, van Dijk T, von Lindren M, Lajos G, Olah E, Nesland JM, Fossa SD, Oosterhuis JW (2003) Stem cell factor receptor (c-KIT) codon 816 transversions predict development of bilateral testicular germ cell tumors. Cancer Res 63: 7674-7678
Mauduit C, Hamamah S, Benahmed M (1999) Stem cell factor/c-kit system in spermatogenesis. Hum Reprod Update 5: 535-545

Pignon JM, Giraudier S, Duquesnoy P, Jouault H, Imbert M, Vainchenker W, Vernant JP, Tulliez M (1997) A new c-kit mutation in a case of aggressive mast cell disease. $\mathrm{Br}$ J Haematol 96: 374-376

Przygodzki RM, Hubbs AE, Zhao FQ, O'Leary TJ (2002) Primary Mediastinal Seminomas: Evidence of Single and Multiple KIT Mutations. Lab Invest 82: $1369-1375$

Rapley EA, Crockford GP, Teare D, Biggs P, Seal S, Barfoot R, Edwards S, Hamoudi R, Heimdal K, Fossa SD, Tucker K, Donald J, Collins F, Friedlander M, Hogg D, Goss P, Heidenreich A, Ormiston W, Daly PA, Forman D, Oliver TD, Leahy M, Huddart R, Cooper CS, Bodmer JG (2000) Localization to Xq27 of a susceptibility gene for testicular germcell tumours. Nat Genet 24: $197-200$

Rubin BP, Singer S, Tsao C, Duensing A, Lux ML, Ruiz R, Hibbard MK, Chen CJ, Xiao S, Tuveson DA, Demetri GD, Fletcher CDM, Fletcher JA (2001) KIT activation is a ubiquitous feature of gastrointestinal stromal tumors. Cancer Res 61: 8118-8121

Strohmeyer T, Reese D, Press M, Ackermann R, Hartmann M, Slamon D (1995) Expression of the c-kit proto-oncogene and its ligand stem cell factor (SCF) in normal and malignant human testicular tissue. J Urol 153: $511-515$

Tian Q, Frierson Jr HF, Krystal GW, Moskaluk CA (1999) Activating c-kit gene mutations in human germ cell tumors. Am J Pathol 154: 1643-1647 